\title{
High Power Laser for Treatment of Achilles Tendinosis - a Single Blind Randomized Placebo Controlled Clinical Study
}

\author{
Anders Mårdh ${ }^{1 *}$, Iréne Lund ${ }^{2}$ \\ ${ }^{1}$ Fysioterapiteamet, Drottningatan 88 F, SE-111 36 Stockholm, Sweden \\ ${ }^{2}$ Department of Physiology and Pharmacology, Karolinska Institutet, SE-17177 Stockholm, Sweden
}

\author{
*Correspondence to \\ Anders Mårdh, MSc; \\ Fysioterapiteamet, Drottningatan 88 \\ F, SE-111 36 Stockholm, Sweden. \\ Tel: +46- 6980942; \\ Fax:+46- 50109517; \\ Email: anders@fysioterapiteamet.se
}

Published online 27 March 2016

\begin{abstract}
Introduction: Pain in the Achilles tendon during loading is a very common condition. Conservative treatments, such as low level laser therapy (LLLT) have been reported to give varying results. Recently, a new laser treatment technique, high power laser treatment (HPLT) (Swiss DynaLaser $($ )), was introduced in Scandinavia, but has not, to our knowledge, been systematically tested before. The objective of this study was to evaluate the effects of HPLT compared to placebo HPLT in rated pain and assessed pain threshold in patients with chronic Achilles tendinosis.

Methods: The study was a randomized, single blind, placebo controlled trial. Patients were randomized to receive 6 treatments of either HPLT or placebo HPLT during a period of 3-4 weeks with a follow up period of 8-12 weeks. Outcome measures were rated pain according to questions of the Foot and Ankle Outcome Score (FAOS, Swedish version LK1.0) and assessment of electro-cutaneous stimulated pain threshold and matched pain (PainMatcher).

Results: The results of the study demonstrated significant changes of assessments within groups, that were more pronounced towards lower levels of rated pain in the HPLT group than in the placebo HPLT group. The between group difference were significant in four of nine questions regarding loading activities of the FAOS subscale. Assessed pain thresholds were found increased in the HPLT group, as compared to the placebo HPLT group. At individual level, the results varied.

Conclusion: The results indicate that HPLT may provide a future option for treatment of Achilles tendinosis related pain, but further studies are warranted.

Keywords: Tendinosis; Pain; Laser.
\end{abstract}

\section{Introduction}

Achilles tendinosis is a common clinical painful condition characterized by pain during loading and appears both among elite athletes, as well as among adult persons with a sedentary lifestyle..$^{1-3}$ Although it is a common clinical condition, its causes and causal mechanisms are still unclear. The Achilles tendon pain, often long-term, does not always clearly reflect the pathological changes in the local tissue. ${ }^{4}$ The condition has been termed "tendonitis" and "tendinitis,"5-8 indicating the possible association with acute inflammatory processes. ${ }^{9}$ Others ${ }^{2}$ did not find any signs of acute inflammation but increased amounts of inter-fibrillar glycosaminoglycans and changes in the collagen fibre structure, possibly accounting for a later stage in the inflammatory process; and the terms "degenerative changes," "chronic tendinopathy" and "tendinosis" have been used. Furthermore, changes in the metabolism of the tendon cells, the tenocytes, and tissue remodeling based on interaction with biomarkers like neurotrophins and tumor necrosis factor alpha (TNF- $\alpha),{ }^{10}$ has been reported to contribute to the condition. Tendinosis is the chosen term in the present work since Alfredson and Lorentzon ${ }^{2}$ suggested that the previously described terms could be used interchangeably, since they probably describe the same or almost the same condition. Multiple risks and possible predisposition factors for Achilles tendinosis have recently been discussed, such as mal alignment in the lower extremity, reduced range of movement in the subtalar and the talocrural joints, increased forefoot pronation and inversion, decreased dorsal flexion with extended knee and varus deformation in the forefoot. ${ }^{11-14}$ Extrinsic factors such as change of load, intensity and distance in exercise programs could also be sources for development of the condition. ${ }^{15}$

Clinically, the diagnosis Achilles tendinosis is based on the medical history including the patients' location of pain approx. 2-6 cm above the tendon insertion into the calcaneus bone, local pain by palpation and functional 
testing. A common clinical finding is furthermore a palpable sore nodular thickening in the tendon, $1.5-7.0 \mathrm{~cm}$ proximal to the insertion into the calcaneus bone. ${ }^{12} \mathrm{How}-$ ever, it appears that there is a lack of clear inclusion criteria and consensus in how to diagnose chronic Achilles tendinosis. Hutchison et al ${ }^{16}$ suggested the use of musculoskeletal ultrasound scanning (MSKUS) to be added for diagnose.

Multiple conservative types of treatment for Achilles tendinosis have been reported, but the interpretation of its effects are complicated by the inconsistency of diagnostic criteria. However, heavy load eccentric exercises appear to be an effective treatment modality, but seem to be time-consuming and difficult for some patients to comply with. ${ }^{2}$ Thus, it would be of value to find less time-consuming and less patient demanding treatments with effects on the perceived pain. Different types of laser treatment could be an alternative. The effects of low level laser therapy (LLLT) have been described to influence inflammation, angiogenesis, promote collagen synthesis and to reduce cell apoptosis. ${ }^{17}$ Thereby, the treatment can aid in recovery of the tendon injury, ${ }^{18-20}$ that in turn can contribute to decrease the related perceived pain, and possibly also increased activity in the endogenous pain inhibiting system.

Recently, a newly developed laser technique, high power laser treatment (HPLT), based on a laser class 3B, infrared $980 \mathrm{~nm}$ gallium arsenide laser, was introduced in Scandinavia for treatment of pain induced by musculoskeletal injuries. The HPLT is equipped with an electrical cooling system which allows delivery of higher energy levels in shorter time periods, compared to conventional laser systems. The wavelength is also of importance for the depth of penetration in tissue. Bjordal et al identified a therapeutic window for effect in the range of $2-10 \mathrm{~J} / \mathrm{cm}^{2}$ within 810 to $830 \mathrm{~nm}$ wavelength, ${ }^{21}$ i.e. using Laser equipment with shorter wavelength than the HPLT. No established treatment protocol or evaluation of HPLT for pain treatment in patients with Achilles tendinosis has been reported earlier.

The purpose of this study was to evaluate the changes in different aspects of pain, i.e. perceived pain frequency and intensity, in patients with long-term signs of Achilles tendinosis, after treatment with HPLT (Swiss DynaLaser ${ }^{\circledR}$ ) and placebo HPLT. The patients' pain threshold and their physically matched pain were also assessed (see method section).

\section{Methods}

This was a randomized, single blind, placebo-controlled trial that was carried out within the framework of a Master's program and could, therefore, just receive an advisory opinion from the local ethical board in Stockholm, who stated that they could not see any ethical obstacle to the execution of the proposed project, dnr 2012/1985-31/1.

\section{Participants}

The participants were recruited through three differ- ent methods: request to external physiotherapy clinics $(\mathrm{n}=4)$, advertisement on social media sites for sport injuries, http://www.jogg.se/ $(n=24)$, http://www.funbeat. $\mathrm{se} /(\mathrm{n}=8)$, and from the first author's clinic waiting-list $(n=6)$. All interested participants received the site address to a specially designed website with background information, objective of the trial and the informed consent form (http://fysioterapiteamet.se/laserstudien.html). Participants with symptoms of long-term Achilles tendinosis described in Table 1, were considered candidates for inclusion after giving their informed consent to participate. After approval of participation, the patients signed the informed consent at the first meeting. Forty-two patients were recruited consecutively.

\section{Randomization Procedure}

Participants were randomized to either HPLT or placebo HPLT by randomly selecting one of two unmarked sealed envelopes. The baseline data of the randomized participants are presented in Table 2. The note inside the envelope was just marked A (placebo HPLT) or B (HPLT) without giving any information which group the two letters represented.

\section{Physical Examination}

The presence of Achilles tendinosis was defined as: an area of swelling in the Achilles tendon, tenderness of the

Table 1. Eligibility and Exclusion Criteria of Participating Patients

\begin{tabular}{l}
\hline Eligibility \\
\hline Age, 20-70 years \\
Pain from the Achilles tendon $\geq 2$ months prior to treatment \\
Signed informed consent \\
MSKUS signs of Achilles tendinosis \\
Exclusion criteria \\
Other diseases or conditions: \\
Malignant diseases; diabetes type 1 (polyneuropathy \\
in the lower extremity); rheumatology diseases; acute \\
inflammation near the Achilles tendon; monogenic familiar \\
hypercholesterolemia; pregnancy \\
Other treatments of the condition: \\
Steroid injection 6 months before HPLT; extra corporal \\
focused shockwave treatment 3 months before HPLT; earlier \\
surgery; intake of NSAIDs 4 weeks before HPLT
\end{tabular}

Abbreviations: HPLT, high power laser treatment; NSAIDs, nonsteroidal anti-inflammatory drugs; MSKUS, musculoskeletal ultrasound scanning.

Table 2. Descriptive Data of the Participants

\begin{tabular}{lcc}
\hline Variables & $\begin{array}{c}\text { Placebo HPLT, } \\
\mathbf{n}=\mathbf{1 9}\end{array}$ & $\begin{array}{c}\text { HPLT, } \\
\mathbf{n = 2 1}\end{array}$ \\
\hline Age (years), mean (SD) & $47.4(8.1)$ & $41(8.3)$ \\
Gender (w; m), $\mathrm{n}$ & $12 \mathrm{w} ; 9 \mathrm{~m}$ & $14 \mathrm{w} ; 7 \mathrm{~m}$ \\
MSK sign, $\mathrm{n}(\%)$ & $17(89)$ & $21(100)$ \\
Achilles tendon (mm), mean (SD) & & \\
$\quad$ Longitudinal & $7.4(1.4)$ & $6.7(1.5)$ \\
$\quad$ Transversal & $9.2(3.8)$ & $6.6(2.3)$ \\
Oedema, n (\%) & $18(95)$ & $19(90)$ \\
Tenderness by palpation, $\mathrm{n}(\%)$ & $18(95)$ & $21(100)$ \\
Pain in heel lifting, n (\%) & $15(79)$ & $17(81)$ \\
\hline
\end{tabular}

Abbreviation: HPLT, high power laser treatment. 
tendon during palpation, pain in the affected side during active heel lift standing on one leg, signs of tendinosis changes in MSKUS. Presence of three of these criteria confirmed the diagnosis.

\section{Musculoskeletal Ultrasound Scanning}

MSKUS was performed by using a linear high frequency transducer (Prosonix MSK ultrasound scanner) applied to the skin with contact gel. Visions of the Achilles tendon, from musculo-tendinous junction to the distal insertion on the calcaneus bone, were obtained in two orthogonal planes. The thickest point of the tendon in the transversal and longitudinal planes was noted. MSKUS measurements were made bilateral for comparison between the two sides.

\section{Intervention}

The HPLT or placebo HPLT was given at 6 sessions during 3-5 weeks. The placebo HPLT was distributed utilizing a second laser unit without active laser, but with visual and acoustic warning identical to the active HPLT equipment. The same physiotherapist (AM) treated all the participants. To maintain the participants blinding, both the HPLT unit and the placebo HPLT unit produced a sound and a visible red light during treatment and no information was communicated regarding group affiliation, i.e. all participants were given treatments under the same conditions. Before the first treatment, possible side effects were presented to the participants stating they could feel warmth, rubbing, tingling or some discomfort and they were asked to avoid any eccentric exercise during intervention and follow up periods. During the treatments, the participants were placed in a prone position with extended hip and knee, and the ankle in maximal dorsal flexion.

\section{High Power Laser Treatment Equipment}

The treatment protocol was chosen on the basis of recommendations from the manufacturer and AM's clinical experience, Table 3. For the HPLT, Swiss DynaLaser ${ }^{\circledR}$ infrared $980 \mathrm{~nm}$ gallium arsenide laser equipment was used. The HPLT was delivered with skin contact and slight pressure on 5 points per side over the painful area, which was repeated twice each session. First round/session was delivered with $17 \mathrm{~J} /$ point and a second round/session was delivered with $35 \mathrm{~J} /$ point. Total energy delivered per session was $520 \mathrm{~J}$ (Manufacturer: HP-Swiss Medical; info@ hp-medical.com), Table 3. For placebo HPLT a second unit without active laser was used with all other procedures identical to the active HPLT.

\section{Outcome Measures}

The participants rated their pain (frequency and intensity), assessed their pain threshold and their matched pain, at baseline and at 8-12 weeks follow-up after the randomization.

\section{Rated Pain}

The five verbal category Pain subscales of the self-as-
Table 3. Technical/Treatment Data With HPLT (Swiss DynaLaser ${ }^{\circledR}$ )

\begin{tabular}{ll}
\hline Technical Data & \\
\hline Voltage & $230 \mathrm{~V} \mathrm{AC}$ \\
Frequency & $50 \mathrm{~Hz}$ \\
Current & $2.85 \mathrm{Amp}$ \\
Output & Infrared $980 \mathrm{~nm} / 660 \mathrm{~nm}$, \\
& Gallium Arsenide \\
Output & $0.1 \mathrm{n} 9.9 \mathrm{KHz} / 0.25-35 \mathrm{~J} /$ \\
& $\mathrm{cm}^{2}$ \\
ON/OFF & Key switch/Footswitch \\
Warning/CE & Visual and acoustic warning \\
& tone/0123 \\
Treatment data & $0.78 \mathrm{~cm}{ }^{2}$ \\
Irradiation area spot size & $980 \mathrm{~nm}$ \\
Wavelength & $10 \times 2$ rounds \\
Number of irradiation points & $17 \mathrm{~J}$ \\
Energy/point in first round & $35 \mathrm{~J}$ \\
Energy/point in second round & $520 \mathrm{~J}$ \\
Total energy/session & $3120 \mathrm{~J}$ \\
Total energy in 6 sessions & Skin contact, slight pressure \\
Irradiation technique & on 10 points on each side \\
& over painful area repeated \\
twice/session
\end{tabular}

Abbreviation: HPLT, high power laser treatment.

sessment form Foot and Ankle Outcome Score (FAOS) (Swedish version LK1.0) was used for assessment of the perceived pain in different situations. The pain subscale consists of nine different questions where the first question is related to the frequency of perceived pain (How often do you experience foot/ankle pain?), which responses are: Never, Monthly, Weekly, Daily, Always. The remaining 8 questions relate to the experienced intensity of the pain during the last week, which was rated by the following verbal alternatives - None, Mild, Moderate, Severe, Extreme. In the data sheet the categories were recorded as 0 to 4 .

Pain Threshold and Matched Pain

Pain threshold and perceived matched pain were assessed utilizing the instrument PainMatcher (PainMatcher ${ }^{\circledR}$, Cefar Medical AB, Lund, Sweden) that has shown good reliability and validity. ${ }^{22,23}$ PainMatcher gives an electro-cutaneous stimulation to the skin of two fingers, the index finger and the thumb in one hand. The increase in the constant current generation of the PainMatcher is interrupted when the person releases the fingers from the stimulation electrode and a value, PM value, between 0 and 99 (arbitrary units but directly related to the pulse width) is displayed on the LCD screen on the instrument. The pain threshold is assessed when the patient experiences the least sensation of pain. Matched pain is assessed when the patient feels that the intensity of the electric-cutaneous sensation matches the actual pain intensity experienced in the Achilles tendon.

Statistical Methods

The mean value and standard deviation (SD) were calculated for quantitative variables, and rated experiences were 
given as median and range (minimum to maximum). The pattern of change in the paired assessments between baseline and follow-up are described in Table 4, Figures 1 and 2 while pain threshold and matched pain are described in scatterplots, Figures 2 and 3. The main diagonal in the scatter plots from the lower left corner to the upper right indicates no change between the two occasions. Results below the diagonal means lower pain threshold or lower matched pain after treatment.

For analysis of changes within and between the groups, the method by Svensson was used. ${ }^{24,25}$ A measure of systematic change in the paired assessments (before and at follow-up), related to the respective group, was calculated and is named relative position (RP). Possible values of $\mathrm{RP}$ range from -1 to 1 . Values close to zero indicate lack of systematic group change. Negative RP values indicate systematic group change towards lowered assessed levels at follow-up. Additional individual variations in change that is unexplained by the RP value, are expressed by the RV (relative rank variance), ranging from 0 to 1 (no additional individual changes to complete additional individual changes). The RP and RV with their 95\% CI)were calculated. ${ }^{24,25}$ Statistically significant measures are evident by CIs not covering zero value. Analyses of possible differences in systematic changes in assessments between groups, $\Delta \mathrm{RP}$, was also calculated. Two-sided $\mathrm{P}<0.05$ corrected with Bonferroni-Holm adjustment for multiple tests $^{26}$ was regarded as significant. Statistica 12 (Statsoft ${ }^{\circledR}$, USA) was used for descriptive statistics and Excel macro was used for the analysis with the method by Svensson. ${ }^{25}$

\section{Drop out}

Of the eligible patients, 4 of them (2 patients from each group) dropped out. One patient in the placebo HPLT group dropped out without explanation and one patient was not willing to stop with eccentric exercises. One pa- tient in the HPLT group chose not to continue before starting treatment without any explanation and one patient did not show up at follow up. The patient contacted the clinic later and explained that not showing up was pure oblivion, Figure 4.

\section{Results}

Of the 40 included patients, 25 women and 15 men, with a mean age of 43.8 (9.1) years, 19 were randomized to the placebo HPLT group and 21 to the HPLT group. The diagnostic signs of swelling, tenderness by palpation, provoked pain in the local area by heel lifting in standing on one leg and ultrasounds scanning were present in a majority of the patients in both groups. Furthermore, the MSKUS assessments demonstrated signs of tendinosis changes in 17 patients (89\%) in the placebo HPLT group and 21 patients (100\%) in the HPLT group, Table 1.

\section{Pain}

The first question in the pain subscale, "How often," was rated significantly lower by the patients in the HPLT group at follow-up (median: Weekly, range: never to weekly) as compared to the patients in the placebo HPLT group (median: Daily, range: weekly to always), $P=0.001$. The responses to "Bending fully," "Walking on flat surface" and "Standing upright," showed similar differences in change of rated painful aspects between the groups (Table 4, Figure 1).

\section{Pain Threshold}

As evident from Figure 2, the assessed pain threshold was decreased or unchanged in three of 18 individuals in the HPLT group and in nine of 17 individuals in the placebo HPLT group after treatment. Significant change in the assessed pain threshold towards higher values was found in the HPLT group, RP 0.35 (95\% CI: 0.12 to 0.57$)$, with

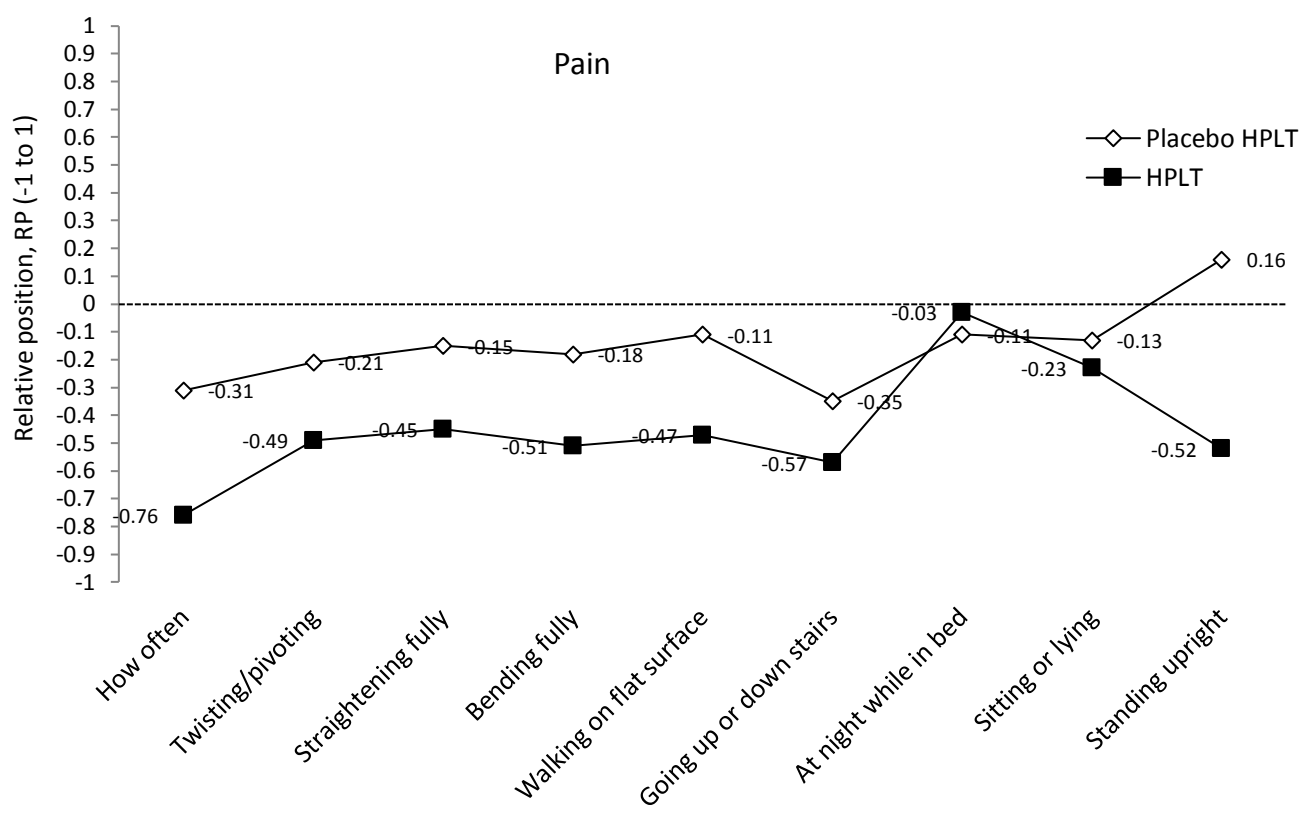

Figure 1. Relative Position (RP) Profiles of Self-rated Pain Items of the Foot and Ankle Outcome Score (FAOS). 

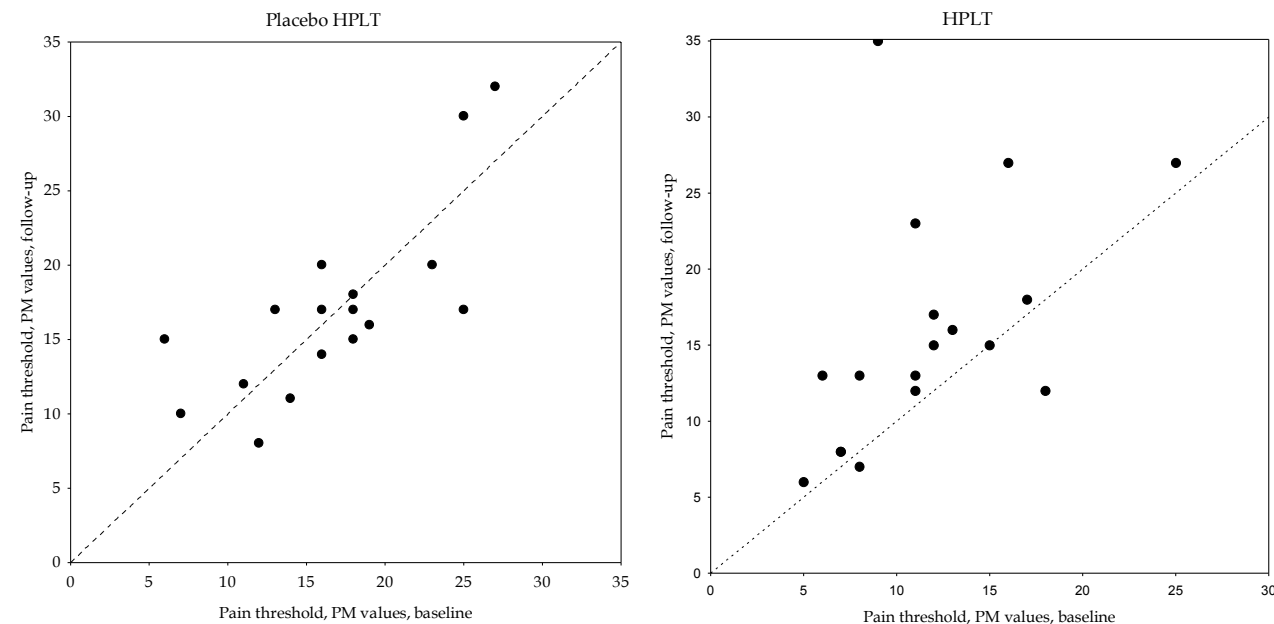

Figure 2. Paired Data of Pain Threshold Assessment Given as PainMatcher (PM) Values for the Two Groups Respectively.
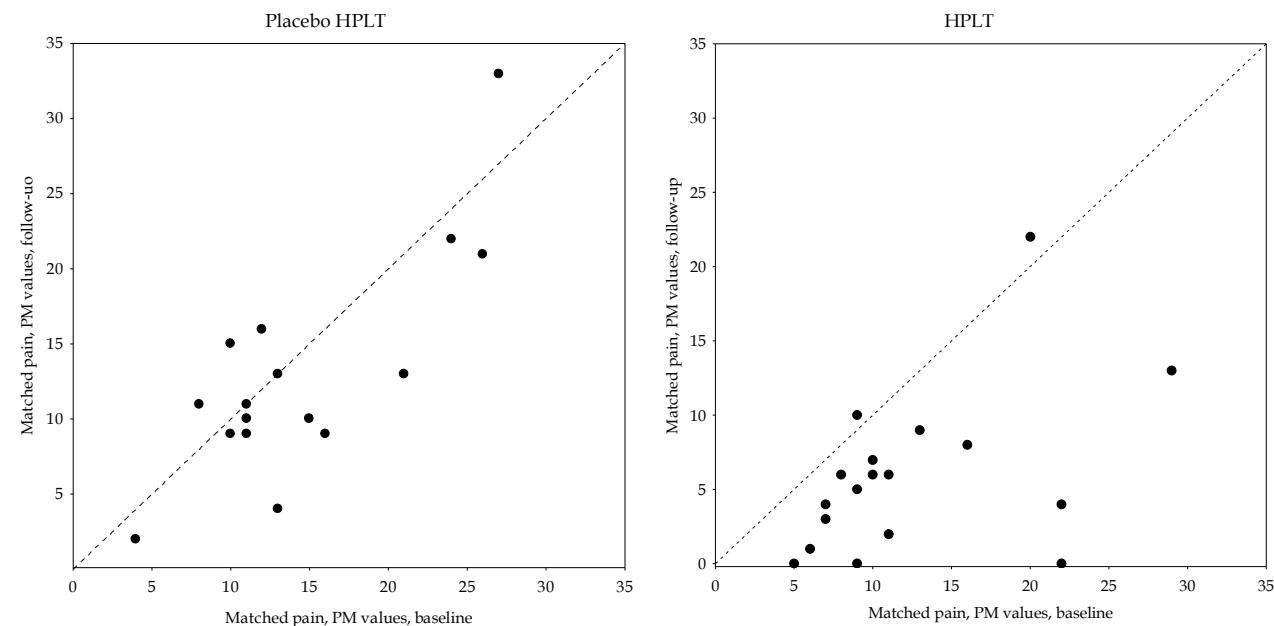

Figure 3. Paired Data of Matched Pain Assessment Given as PainMatcher (PM) Values for the Two Groups Respectively.

additional individual variations, RV 0.35 (95\% CI: 0.00 to 0.69 ). No such systematic group change was found in the placebo HPLT group, RP -0.02 (95\% CI: -0.22 to 0.17 ). The observed changes are attributed to individual variations, RV 0.17 (95\% CI: 0.03 to 0.30). The difference in systematic changes in pain threshold between groups, $\Delta$ $\mathrm{RP}$, was $0.370, P=0.015$ (Figure 2).

\section{Matched Pain}

Matched pain values were found significantly lower in the HPLT group, $\mathrm{n}=18$, at follow up RP -0.65 (95\% CI: -0.94 to -0.36$)$ with large individual variation, RV 0.46 (95\% CI: 0.00 to 1.00$)$. Corresponding individual variations were found in the Placebo HPLT group, RV 0.60 (95\% CI: 0.04 to 1.00 ), but systematic change was not evident, RP -0.27 (95\% CI: -0.54 to 0.01 ) (Figure 3). The observed difference in systematic changes in matched pain between groups, $\Delta \mathrm{RP}-0.385$, indicated weak statistical evidence of significant difference between the groups, $P=0.06$.

\section{Discussion}

The results of this single-blind randomized clinical study provides evidences that the patients subjected to HPLT rated significantly less pain in four of nine questions of the FAOS pain subscale (pain: how often, when bending fully, walking on flat surface, when standing upright) as compared to the patients treated with placebo HPLT at follow-up after treatment. Furthermore, the pattern of change showed that the pain-thresholds were significantly higher among the HPLT patients at the group level than among the placebo HPLT patients, when comparing the follow-up with the base-line assessments. The results also demonstrated different response patterns among the individual patients within the two groups, confirmed by great RV values with wide confidential intervals. These individual based variations may indicate that treatments may need to be tailored to the individual regarding e.g. duration of treatment, number of treatments, etc. The decrease in perceived pain and increase in pain thresholds in the HPLT group could be a sign of increased activity in the endogenous pain inhibitory system as a response to the sensory stimulation evoked by this type of laser therapy.

In this study, pain was rated lower already at 8 weeks after 




Figure 4. Flow Chart of Participating Patients start of treatment compared to previous studies that have reported reduced pain after 12 weeks of treatment.,27 In a study with LLLT in patients with Achilles tendinosis, a small rise in pressure pain threshold was seen as well as immediate decreased concentrations of prostaglandin E2 in peritendinous tissue, ${ }^{17}$ indicating changes in inflammatory reactions, possibly associated with changed function in the pain system. However, the effects of HPLT on Achilles tendinosis induced pain have not been published earlier.

An interesting finding was that three of the pain questions, all related to loading the Achilles tendon (Bending fully, Walking on flat surface, Standing upright), were rated lower by the HPLT patients than the placebo HPLT patients. However, there was no significant difference between groups in responses to question of pain in: Twisting/pivoting, Straightening fully, At night while in bed, Sitting or lying). This observation indicates that it would be of value to develop more specific selection of pain related questions in order to catch treatment responses of HPLT in patients with Achilles tendinosis.

Bagge $^{10}$ found significant increased levels of neurotrophin and TNF- $\alpha$ in tendons with chronic Achilles tendinosis. Bagge suggested that the functions of these substances include apoptosis, tissue remodeling, and proliferation in tenocytes. In future studies, it would be interesting to also measure changes in the levels of neurotrophin and TNF- $\alpha$ in response to HPLT in patients with chronic Achilles tendinosis. A wide variety of interventions for Achilles tendinosis have been utilized earlier where some of the methods are quite demanding regarding the patients

Table 4. Data of Rated Pain From the Subscale of the FAOS Questionnaire Shown as Median (Min-Max) ${ }^{\mathrm{a}}$

\begin{tabular}{|c|c|c|c|c|c|c|c|}
\hline \multirow{2}{*}{$\begin{array}{l}\text { Questions of FAOS } \\
\text { Subgroup }\end{array}$} & \multicolumn{2}{|l|}{ Placebo } & HPLT, n=17 & \multicolumn{3}{|l|}{ HPLT, $n=18$} & \multirow[b]{2}{*}{$\begin{array}{c}\Delta \mathrm{RP}, \mathrm{P} \text { Val- } \\
\text { ues }\end{array}$} \\
\hline & Base-Line & Follow-up & $\begin{array}{l}\text { RP }(95 \% \mathrm{CI}) \\
\operatorname{RV}(95 \% \mathrm{CI})\end{array}$ & Base-Line & Follow-up & $\begin{array}{l}\text { RP }(95 \% \mathrm{CI}) \\
\operatorname{RV}(95 \% \mathrm{CI})\end{array}$ & \\
\hline $\begin{array}{l}\text { Pain } \\
\text { 1. How often }\end{array}$ & $3(2-4)$ & $3(0-4)$ & $\begin{array}{c}-0.31(-0.55 \text { to }-0.07) \\
0.11(0.00 \text { to } 0.28)\end{array}$ & $3(2-4)$ & $2(0-2)$ & $\begin{array}{c}-0.76(-0.92 \text { to }-0.59) \\
0.06(0.00 \text { to } 0.17)\end{array}$ & $\begin{array}{c}0.45-; \\
P=0.002\end{array}$ \\
\hline $\begin{array}{l}\text { Pain, when } \\
\text { 2. Twisting/pivoting }\end{array}$ & $1(0-3)$ & $\mathbf{0}(0-3)$ & $\begin{array}{c}-0.21(-0.39 \text { to }-0.04) \\
0.16(0.00 \text { to } 0.40)\end{array}$ & $1(0-3)$ & $\mathbf{0}(0-3)$ & $\begin{array}{c}-0.49(-0.67 \text { to }-0.31) \\
0.02(0.00 \text { to } 0.07)\end{array}$ & $\begin{array}{c}-0.28 \\
P=0.126\end{array}$ \\
\hline 3. Straightening fully & $1(1-3)$ & $1(1-2)$ & $\begin{array}{c}-0.15(-0.33 \text { to } 0.02) \\
0.04(0.00 \text { to } 0.14)\end{array}$ & $1(0-4)$ & $\mathbf{0}(0-2)$ & $\begin{array}{c}-0.45(-0.63 \text { to }-0.26) \\
0.02(0.00 \text { to } 0.05)\end{array}$ & $\begin{array}{c}-0.30 \\
P=0.054\end{array}$ \\
\hline 4. Bending fully & $1(0-2)$ & $1(0-2)$ & $\begin{array}{c}-0.18(-0.36 \text { to } 0.01) \\
0.02(0.00 \text { to } 0.07)\end{array}$ & $1(0-3)$ & $\mathbf{0}(0-3)$ & $\begin{array}{c}-0.51(-0.69 \text { to }-0.32) \\
0.00(0.00 \text { to } 0.00)\end{array}$ & $\begin{array}{c}-0.33 \\
P=0.048\end{array}$ \\
\hline $\begin{array}{l}\text { 5. Walking on flat } \\
\text { surface }\end{array}$ & $1(0-4)$ & $1(0-3)$ & $\begin{array}{c}-0.11(-0.29 \text { to } 0.06) \\
0.16(0.00 \text { to } 0.42)\end{array}$ & $2(0-4)$ & $\mathbf{0}(0-3)$ & $\begin{array}{c}-0.47(-0.66 \text { to }-0.29) \\
0.11(0.00 \text { to } 0.33)\end{array}$ & $\begin{array}{c}-0.36 \\
P=0.029\end{array}$ \\
\hline $\begin{array}{l}\text { 6. Going up or down } \\
\text { stairs }\end{array}$ & $2(0-3)$ & $1(0-3)$ & $\begin{array}{c}-0.35(-0.52 \text { to }-0.17) \\
0.46(0.00 \text { to } 0.93)\end{array}$ & $2(0-3)$ & $1(0-3)$ & $\begin{array}{c}-0.57(-0.75 \text { to }-0.38) \\
0.20(0.00 \text { to } 0.42)\end{array}$ & $\begin{array}{c}-0.22 \\
P=0.285\end{array}$ \\
\hline $\begin{array}{l}\text { 7. At night while in } \\
\text { bed }\end{array}$ & $\mathbf{0}(0-3)$ & $\mathbf{0}(0-2)$ & $\begin{array}{c}-0.11(-0.28 \text { to } 0.07) \\
0.00(0.00 \text { to } 0.00)\end{array}$ & $\mathbf{0}(0-4)$ & $\mathbf{0}(0-2)$ & $\begin{array}{c}-0.03(-0.21 \text { to }-0.05) \\
0.01(0.00 \text { to } 0.02)\end{array}$ & $\begin{array}{c}-0.08 \\
P=0.936\end{array}$ \\
\hline 8. Sitting or lying & $\mathbf{0}(0-3)$ & $\mathbf{0}(0-1)$ & $\begin{array}{c}-0.13(-0.31 \text { to } 0.05) \\
0.01(0.00 \text { to } 0.05)\end{array}$ & $\mathbf{0}(0-3)$ & $\mathbf{0}(0-3)$ & $\begin{array}{c}-0.23(-0.42 \text { to }-0.05) \\
0.01(0.00 \text { to } 0.04)\end{array}$ & $\begin{array}{c}-0.10 \\
p=0.465\end{array}$ \\
\hline 9. Standing upright & $\mathbf{0}(0-3)$ & $1(0-3)$ & $\begin{array}{c}0.16(-0.02 \text { to } 0.33) \\
0.07(0.00 \text { to } 0.22)\end{array}$ & $1(0-3)$ & $\mathbf{0}(0-3)$ & $\begin{array}{c}-0.52(-0.71 \text { to }-0.34) \\
0.14(0.00 \text { to } 0.37)\end{array}$ & $\begin{array}{c}-0.36 \\
P<0.0001\end{array}$ \\
\hline
\end{tabular}

Abbreviation: FAOS, Foot and Ankle Outcome Score.

a Systematic group changes are shown as RP $(95 \% \mathrm{Cl})$ and individual variability (dispersion in change) as $\mathrm{RV}(95 \% \mathrm{Cl})$ from the Svensson method. Response alternative to question 1: Never (0), Monthly (1), Weekly (2), Daily (3), Always (4); question 2-9: None (0), Mild (1), Moderate (2), Severe (3), Extreme (4). 
compliance. ${ }^{27}$ The most optimized treatment method for the condition is not yet established.

There are some limitations in the current study. One limitation is the low number of participants in each group and that the patients were heterogeneous regarding activity level, symptom duration, age and gender. Another limitation was that the therapist was not blinded to the patients' allocation to different groups, since the active laser unit was also used in daily clinic routine and thereby not possible to blind the therapist. However, actions to secure valid routines during the study were taken by not communicating information with the patients beyond a standardized manuscript.

\section{Conclusion}

The result of this study demonstrated that patients with painful Achilles tendinosis treated with high power laser rated lower pain and assessed higher pain threshold at follow-up after the treatment in comparison with patients treated with placebo high power laser. HPLT may provide a future option for treatment of Achilles tendinosis, but further studies are warranted.

\section{Ethical Considerations}

The ethics committe in Stockholm has stated that they could not see any ethical obstacle to the execution of the proposed project, dnr 2012/1985-31/1.

\section{Conflict of Interests}

The authors certify that they have no personal or professional relationship, knowledge, affiliations or beliefs nor any financial interest (such as stock ownership, honoraria or other equity interest) in the subject matter or materials discussed in this manuscript.

\section{References}

1. Galloway MT, Jokl P, Dayton OW. Achilles tendon overuse injuries. Clin Sports Med. 1992;11:771-782.

2. Alfredson H, Lorentzon R. Chronic Achilles tendinosis: recommendations for treatment and prevention. Sports Med. 2000;29:135-146. doi:10.2165/00007256-20002902000005.

3. Hoeberigs JH. Factors related to the incidence of running injuries. A review. Sports Med. 1992;13:408-422. doi:10.2165/00007256-199213060-00004.

4. Movin T. Aspects of aetiology, pathoanatomy and diagnostic methods in chronic mid-portion Achillodynia [dissertation]. Stockholm: Karolinska Institutet; 1998.

5. Clancy WG Jr, Neidhart D, Brand RL. Achilles tendonitis in runners:a report of five cases. Am J Sports Med. 1976;4:4657. doi:10.1177/036354657600400202.

6. Nelen G, Martens M, Burssens A. Surgical treatment of chronic Achilles tendinitis. Am J Sports Med. 1989;17:754759. doi:10.1177/036354658901700605.

7. Schepsis AA, Leach RE. Surgical management of Achilles tendinitis. Am J Sports Med. 1987;15:308-315.

8. Williams JG. Achilles tendon lesions in sports. Sports Med. 1986; 3:114-135. doi:10.2165/00007256-198603020-00003.

9. Gross MT. Chronic tendonitis: pathomechanics of injury, factors affecting the healing response, and treatment. $J$ Orthop Sports Phys Ther. 1992;16:248-261. doi:10.2519/ jospt.1992.16.6.248.
10. Bagge J. TNF- $\alpha$ and neurotrophins in Achilles tendinosis [Dissertation]. Umeå: Umeå University; 2013.

11. Kaufman KR, Brodine SK, Shaffer RA, Johnson CW, Cullison TR. The effect of foot structure and range of motion on musculoskeletal overuse injuries. Am J Sports Med. 1999;27:585-593.

12. Kvist M. Achilles tendon injuries in athletes. Sports Med. 1994;18:173-201. doi:10.2165/00007256-19941803000004.

13. Nigg BM. The role of impact forces and foot pronation: a new paradigm. Clin J Sport Med. 2001;11:2-9. doi:10.1097/00042752-200101000-00002.

14. Schmidt-Rohlfing B, Graf J, Schneider U, Niethard FU. The blood supply of the Achilles tendon. Int Orthop. 1992;16:29-31.

15. Kannus P1, Józsa L. Histopathological changes preceding spontaneous rupture of a tendon. A controlled study of 891 patients. J Bone Joint Surg Am. 1991;73:1507-1525.

16. Hutchison AM, Evans R, Bodger O, et al. What is the best clinical test for Achilles tendinopathy? Foot Ankle Surg. 2013;19:112-117. doi:10.1016/j.fas.2012.12.006.

17. Bjordal JM, Lopes-Martins RA, Iversen VV. A randomised, placebo controlled trial of low level laser therapy for activated Achilles tendinitis with microdialysis measurement of peritendinous prostaglandin E2 concentrations. Br J Sports Med. 2006;40:76-80. doi:10.1136/bjsm.2005.020842.

18. Józsa L. Human Tendons: Anatomy, Physiology, and Pathology. Champaign, IL: Human Kinetics; 1997;164 -253.

19. Loevschall H, Arenholt-Bindslev D. Effect of low level diode laser irradiation of human oral mucosa fibroblasts in vitro. Lasers Surg Med. 1994;14:347-354. doi:10.1002/ lsm.1900140407.

20. Salate AC, Barbosa G, Gaspar P, et al. Effect of In-GaAl-P diode laser irradiation on angiogenesis in partial ruptures of Achilles tendons in rats. Photomed Laser Surg. 2005;23:470-475.

21. Bjordal JM, Couppé C, Chow RT, Tunér J, Ljunggren EA. A systematic review of low level laser therapy with locationspecific doses for pain from chronic joint disorders. Aust J Physiother. 2003;49:107-116. doi:10.1016/s00049514(14)60127-6.

22. Lundeberg T, Lund I, Dahlin L, et al. Reliability and responsiveness of three different pain assessments. $J$ Rehabil Med. 2001;33:279-283.

23. Lund I, Lundeberg T, Kowalski J, Sandberg L, Budh $\mathrm{CN}$, Svensson E. Evaluation of variations in sensory and pain threshold assessments by electrocutaneous stimulation. Physiother Theory Pract. 2005;21:81-92. doi:10.1080/09593980590922307.

24. Svensson E. Ordinal invariant measures for individual and group changes in ordered categorical data. Stat Med. 1998; 17;2923-2936.

25. Avdic A, Svensson E. Interactive software supporting Svenssons method. http://avdic.se/ svenssonsmethodenglish.html. Accessed August 6, 2015.

26. Holm, S. A simple sequentially multiple test procedure. Scand J Stat. 1979;6:65-70.

27. Mafi N, Lorentzon R, Alfredson H. Superior short-term results with eccentric calf muscle training compared to concentric training in a randomized prospective multicenter study on patients with chronic Achilles tendinosis. Knee Surg Sports Traumatol Arthrosc. 2001;9(1):42-47. doi:10.1007/s001670000148. 